\title{
Investigating the barriers to growth in the Indian food processing sector
}

\author{
Gaurvendra Singh $^{1}$ (D) Yash Daultani ${ }^{2}$ (D) $\cdot$ Rajendra Sahu $^{1}$
}

Accepted: 23 July 2021 / Published online: 4 August 2021

(c) Operational Research Society of India 2021

\begin{abstract}
The Indian food processing sector (IFPS) has a tremendous capability for growth that can improve the socio-economic conditions of the rural masses. The performance of this sector is lagging behind substantially when compared to other developing nations. This study aims to identify growth barriers at different supply chain (SC) stages in the IFPS. Delphi analysis is performed to find out the barriers in the IFPS. Eighteen growth barriers have been found through expert opinion and extensive literature review spanning across three supply chain tiers: farm level, distribution level, and the consumer level. Further, to prioritize and identify the relative importance of various barriers, the analytic hierarchy process is employed. The results show that the top growth barriers in IFPS are-the lack of standardization and quality in the processed food, rain-dependent farming, and the high cost of cold chain facilities. The novel contribution of this study lies in capturing the intricacies of growth barriers in IFPS in an integrated manner across different SC tiers. Interactions between the identified drivers are important to both practitioners and researchers in understanding and driving process, quality, and technology improvements. Finally, the results also throw light on prioritized areas of concern that can be a game-changer for policymakers in India and other developing nations.
\end{abstract}

Keywords Food supply chain · Growth barriers · Indian food processing sector · Analytic hierarchy process $\cdot$ Delphi analysis

\section{Abbreviations}

$\begin{array}{ll}\text { AHP } & \text { Analytic hierarchy process } \\ \text { CII } & \text { Confederation of Indian Industry } \\ \text { CII-FACE } & \text { The CII Jubilant Bhartia Food and Agriculture Centre of Excellence }\end{array}$

Gaurvendra Singh

gauravs@iiitm.ac.in

1 Management Department, ABV- Indian Institute of Information Technology \& Management Gwalior, Gwalior 474015, India

2 Operations Management Group, Indian Institute of Management (IIM) Lucknow, Lucknow 226013, India 


$\begin{array}{ll}\text { USA } & \text { United States of America } \\ \text { IFPS } & \text { Indian food processing sector } \\ \text { GDP } & \text { Gross domestic product } \\ \text { FL } & \text { Farm-level } \\ \text { DL } & \text { Distribution-level } \\ \text { CL } & \text { Consumer-level } \\ \text { MCDM } & \text { Multiple-criteria decision modeling } \\ \text { RFID } & \text { Radio-frequency identification } \\ \text { CI } & \text { Consistency index } \\ \text { CR } & \text { Consistency ratio } \\ \text { RI } & \text { Random consistency index } \\ \text { DEMATEL } & \text { Decision-making trial and evaluation laboratory } \\ \text { ISM } & \text { Interpretive structural modeling } \\ \text { SEM } & \text { Structural equation modeling } \\ \text { SIDBI } & \text { Small industries development bank of India } \\ \text { FSSAI } & \text { Food safety and standards authority of India } \\ \text { APMC } & \text { Agricultural Produce Market Committees } \\ \text { GOI } & \text { Government of India } \\ \text { NABARD } & \text { National Bank for Agriculture and Rural Development }\end{array}$

\section{Introduction}

India is ranked first in the production of milk, banana, papaya, mango, ginger, pulses, and buffalo meat globally. However, the overall processing level of perishable products stands just at $10 \%$ [10], which significantly limits the processing capability when compared to other nations such as the USA (80\%), France (70\%), and Thailand (30\%). Despite having the advantage of favorable agri-climatic conditions, the Indian food processing sector (IFPS) lags compared to global food processing supply chains in terms of overall productivity. For instance, exports of processed food as a percentage of GDP stand at $2 \%$ for India [4], which is easily noticeable when compared to Brazil (4\%), Argentina (7\%), and Thailand (9\%).

Moreover, the supply chain (SC) gaps and losses are perhaps the biggest challenges faced by the IFPS. Losses occur in the IFPS at multiple levels, such as farm, distribution, and consumer levels. According to Shankar et al. [42], this has emerged as a severe global challenge as around $40-50 \%$ of the world's root crops, fruits, and vegetables are destroyed before consumption. The food processing industry can play a vital role by reducing food losses, productivity improvements, and increasing the shelf life of their products [31]. This can be accomplished by involving all supply chain stakeholders and optimizing the supply chain from beginning to end, resulting in a win-win outcome for all parties involved [13, 14].

The food processing sector is generally divided into two broad areas: processed food and value-added processed food [36, 52]. The first category deals with milk, flour, rice, spices, pulses, vegetables, fruits, and salt that are sold in either packed or unpacked condition. These products have short to medium shelf life depending upon the storage and weather conditions at different supply chain 
stages. There are multiple challenges, such as wastage and contamination in this category, especially with the sold products without packing. The second category contains processed food products such as jams, juices, pickles, processed vegetables and fruits, dairy, poultry, and chocolates. These food products are generally processed using natural and artificial food preservatives before packing and having a long shelf life.

IFPS in itself has a significant growth perspective and tremendous scope for socio-economic development in terms of value addition, trade boost, employment opportunities, and food wastage reduction $[9,22,52]$. The exports of the processed agriculture commodity provide a better return and increase the farmers' income and living standards. Due to its paramount importance, the IFPS has been identified as one of the vital sectors under the 'Make in India' initiative launched by India's Government in 2014. Although there is still a long way to capture untapped opportunities in IFPS, that is not possible without identifying and addressing the barriers to the growth of IFPS [5, 30].

The motivation for this study is that the current state of research in IFPS is staggered and focused on individual SC tiers, as seen in the previous studies. This study identifies the growth barriers in IFPS across various SC tiers. To the best of the authors' knowledge, the novel contribution of this study lies in capturing the intricacies of growth barriers across different SC tiers, namely-farm level, distribution level, and the consumer level. The research questions of this study are as follows.

RQ1: What are the barriers to growth in the Indian Food Processing Sector (IFPS)?

RQ2: What is the relative priority and importance of the identified growth barriers?

Delphi analysis has been performed to find out the barriers in the IFPS. The Analytic hierarchy process (AHP) is then deployed to prioritize these barriers in the IFPS. In the end, policy-level interventions and the interplay of important barriers for researchers and practitioners are analyzed. In summary, the major contributions of the research work are as follows:

i. The present research work uncovers possible growth barriers in the Indian food processing sector through the Delphi technique.

ii. The ranking and relative importance of the identified barriers is determined using the Analytic hierarchy process (AHP).

iii. This research work presents significant insights for researchers, practitioners, and policymakers.

The rest of the article is organized as follows. Section 2 presents the literature review, and Sect. 3 presents the model development. Section 4 discusses the steps involved in applying the Delphi analysis and AHP. The results are summarized in Sect. 5. The work is concluded, and future research directions are also presented in the last section. 


\section{Literature review}

Some important literature related to the Indian food processing sector is discussed in this section. Murthy and Yogesh (2014) identified the challenges and opportunities in the IFPS. Earlier, Singh et al. [49] also identified the issues and challenges in the IFPS and examined the hurdle in the path of IFPS growth. Recently, Persis et al. [32] assessed the impact of circular economy in the food processing industries. As per the study's findings, ethical practices and the internet of things should be encouraged to increase sustainability in food processing. It improves the decision-making in the supply chain and enhances efficiency. Babu et al. [6] spread the awareness required for starting the food processing business and current initiatives and policies in the food processing sector by the Indian government. As per the findings, there is a need to provide training for developing the food processing industries. Das and Biswas [12] explored the role of the food processing sector in the Indian economy and presented the role of IFPS in the future.

Some authors discussed the current issue related to IFPS, like Thulasiraman et al. [50], raised the issues in the food processing sector in pandemic situations like COVID-19 and how to manage the short supply of food in case of a pandemic. The proper balance between food processing industries and the food supply chain can help in achieving sustainability. During lockdown in case of a pandemic situation, it is challenging to provide the raw material for the food processing industries. Similarly, chitrakar et al. [8] identified the role of information technologies in managing food processing industries during a pandemic situation.

Shelly and Kaur [43] assessed the role of IFPS in economic growth and employment. They also suggested that an increase in foreign direct investment, global competitiveness, and export promotion is required to develop the IFPS. Singh et al. [48] presented factors that affect dairy processing. Ali (2007) [3] has analyzed the barriers in the meat processing industry. Reddy and Bantilan [39] have discussed issues that decrease the efficiency of groundnut processing. Sharma et al. [41] examined the problems associated with the dairy green supply chain management industry. To capture the vast issues and contextual complexity in agricultural food supply chains, researchers also using various multiple-criteria decision modeling (MCDM) approaches.

\section{Model development}

The conceptual model for growth barriers in the IFPS is extracted from the existing research studies, added expert opinion, and expert validation. The barriers have been extracted by keeping the broader focus on increasing the productivity and product shelf life supported by efficient food processing that aims to minimize food wastage at various supply chain stages. In particular, short shelf-life agriculture/animal produce (perishable items like fruits, vegetables, dairy products, etc.) and long shelflife produce (wheat, rice, pulses, etc.) are considered for the study. 
The food processing sector is affected by various demand-side factors such as rapid urbanization, changing food habits, and rising demand for frozen food that should be healthy and nutritious. Cleanliness, freshness, flavor, ease of cooking, and taste are other essential product characteristics that play an important part in consumers' purchase decisions [20]. On the supply side, the food industry has to address multiple challenges to minimize food wastage like proper traceability, packaging, cold chain, transportation, etc. Eco-innovation should be adopted to reduce food and packaging waste [46]. Proper traceability is required to monitor the live food condition along the supply chain, such as temperature, humidity, etc., to avoid food spoilage [11]. Studies in the logistics sector, such as Prajapati et al. [33], also throw light on this issue from a transportation perspective.

Upon closer inspection of the existing literature and expert opinion, the barriers are divided into the farm, distribution, and consumer levels. Key issues found at the farm level are low yield, inadequate quality of food produce, conventional farming methods, rain-dependent farming, lack of proper logistics and the handling facilities at the farm, insufficient cold storage facilities near the farm, unaffordable modernization, high advertising cost, and, improper grading. Next, at the distribution level, barriers in the food processing sector were found out to be the high cost of modern transportation facilities, high cost of the cold chain, inadequate information technology and communication support, high cost of packaging, limited market support, lack of government support and poor coordination between farmers and food processor. At the consumer level, the barriers found are lack of awareness, lack of standardization, and quality in processed food and conventional food habits. The complete list of the critical barriers, along with their descriptions, is shown in Table 1. The Delphi technique is a well-known and widely used technique. The steps of the Delphi technique has summarized in the next section in brief.

The existing literature and experts' opinion suggested that more research is needed in the Indian food processing sector. This work aims to fill some of the existing research gaps by finding critical barriers in the Indian food processing sector (IFPS). The Delphi technique is used to capture the expert opinion. The conceptual model is shown in Fig. 1. Further, the analytic hierarchy process (AHP) ranks and identifies the relative importance among various barriers.

\section{Research methodology}

This research paper uses the Delphi analysis and the AHP technique to achieve the research objectives. Steps involved in the Delphi analysis and AHP are given below:

\subsection{Delphi analysis}

The RAND Corporation developed the Delphi analysis technique in 1950 [27]. It is a judgemental technique. In this technique group of experts discuss the problem and come with a common opinion for decision making. It is advantageous when there is inadequate theoretical development (Bouzon et al., 2016). Various researchers and 


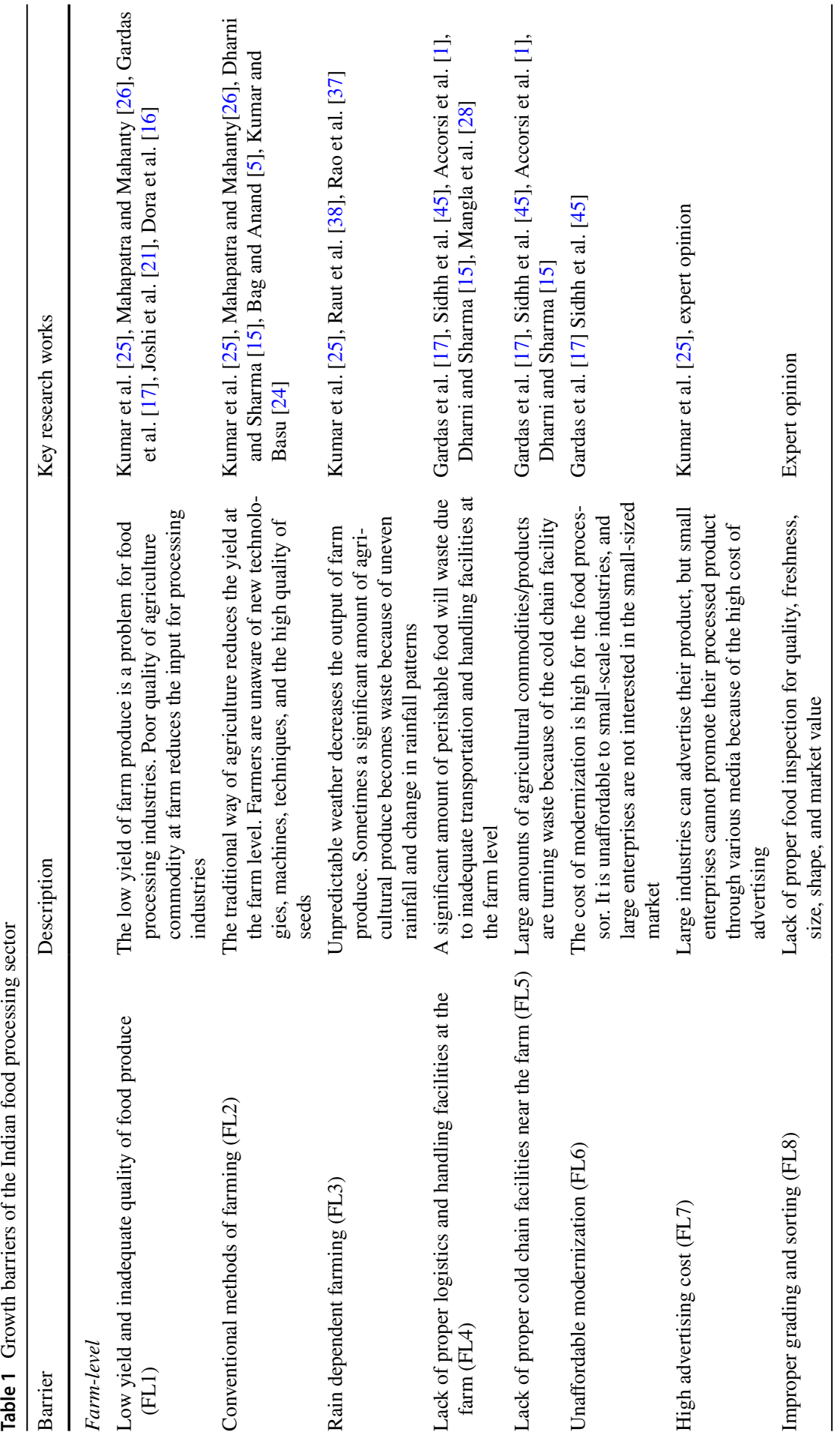




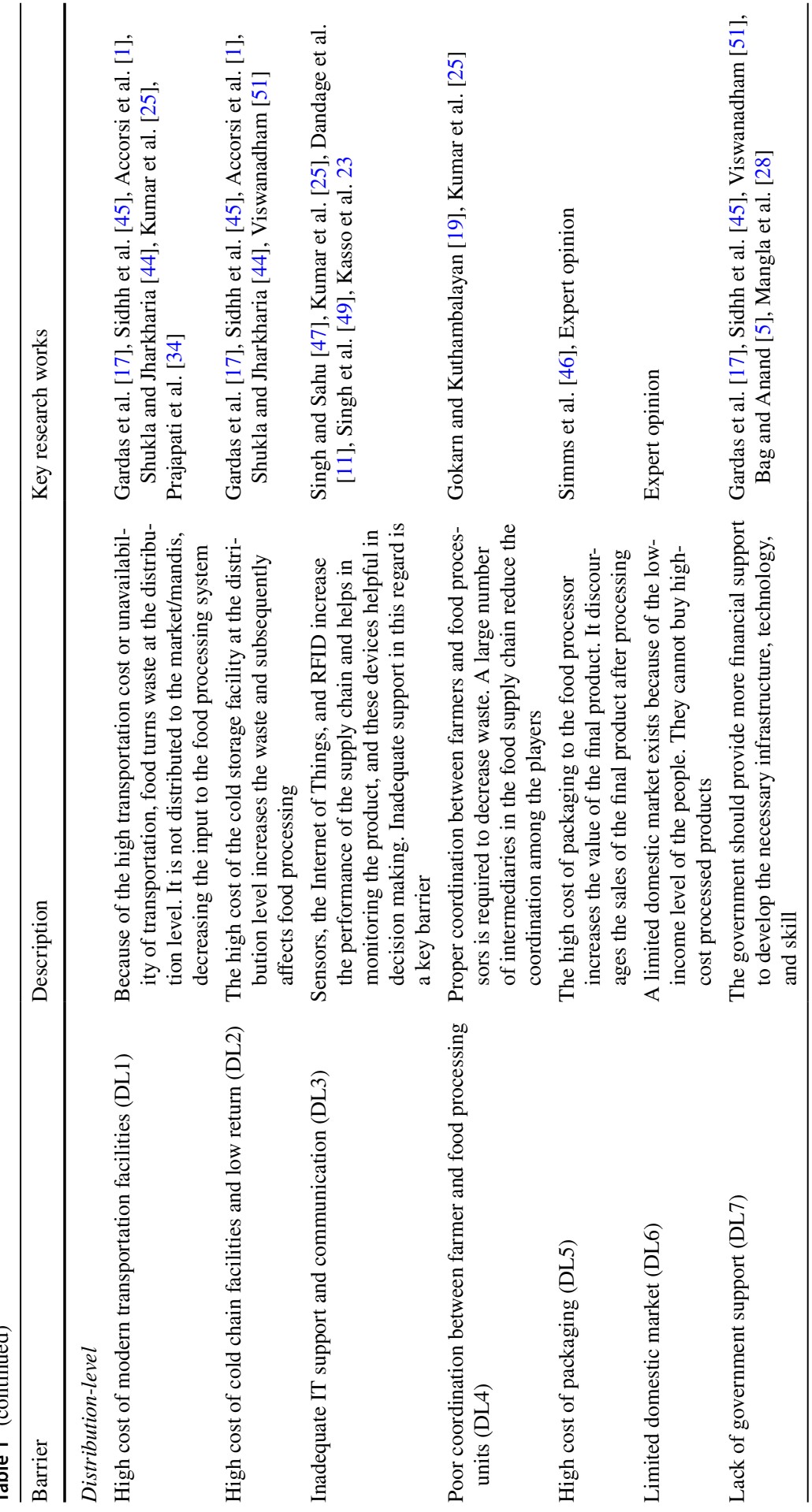




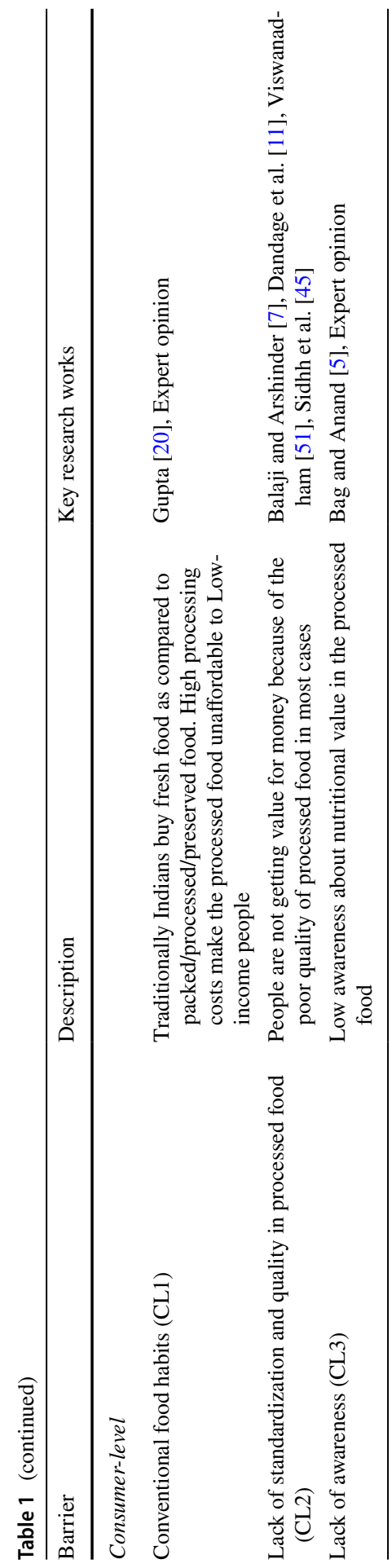




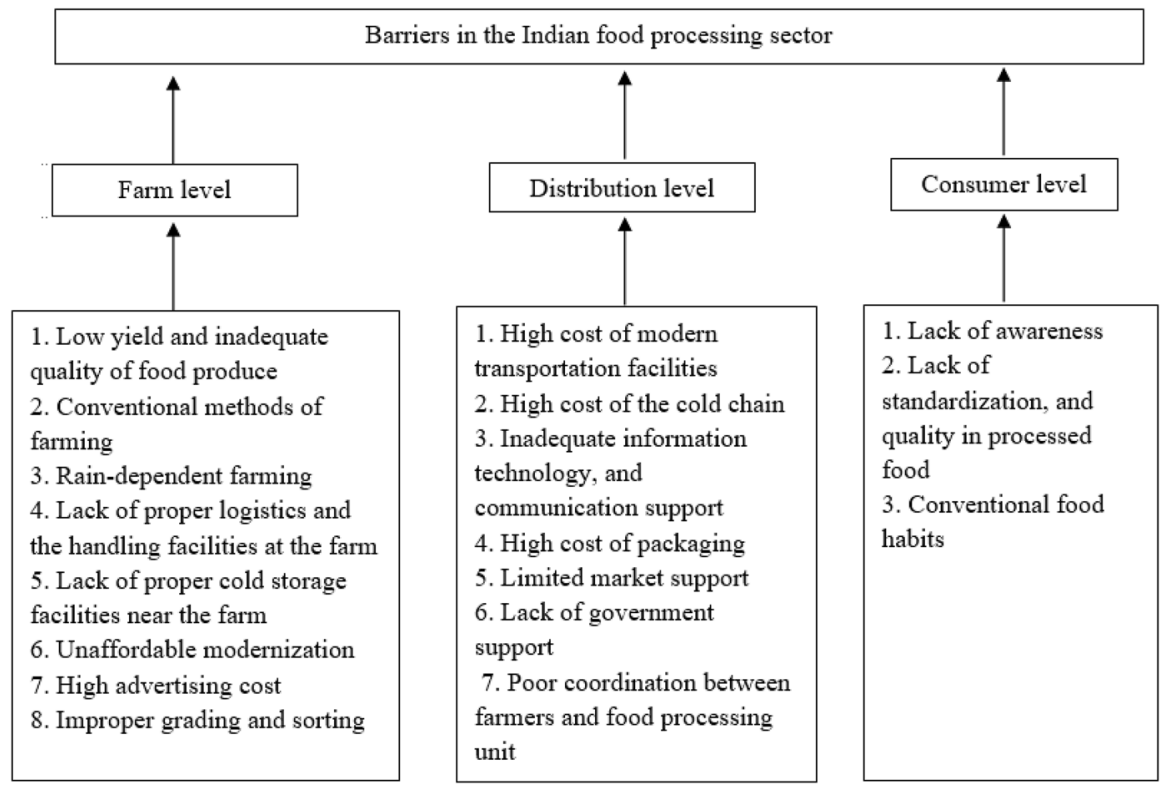

Fig. 1 The conceptual model for barriers in the Indian food processing sector

practitioners widely use it for analyzing complex decision problems. In this method, decision-making depends upon human judgment. The steps involved in this paper for the Delphi technique are (see, Akkermans et al. [2]).

i. Identification of the research problem and questionnaire design to analyse the problem.

ii. Search for experts related to the research problem to be analyzed. The experts are approached and asked for information related to the issues in the questionnaire format.

iii. Experts give some ideas and possible solutions about the barriers in the Indian food process sector.

iv. Responses are collected from each expert. Received responses are reviewed and analyzed with the proper feedback.

v. The expert is contacted again, and the process is repeated until the consent of all experts is reached. Finalize the barriers after the consent of all the experts'. Finalized growth barriers are shown in Table 1.

\subsection{Analytic hierarchy process (AHP)}

It is a multi-criteria decision-making (MCDM) technique used for solving a complex problem. Saaty developed AHP in 1980, and AHP is used to model and rank factors in various fields like management, manufacturing, industry, government, engineering, etc. Managers, researchers, and practitioners use it by arranging a 


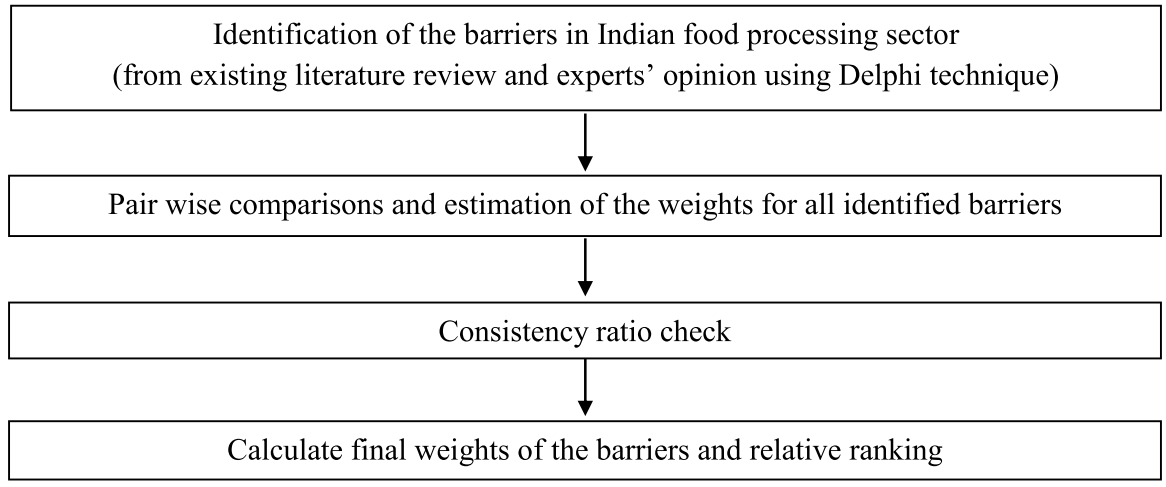

Fig. 2 AHP flowchart

Table 2 Scales in pairwise comparisons [40]

\begin{tabular}{ll}
\hline Score & Definition \\
\hline 1 & Equal importance of both factors \\
3 & Limited importance of one factor over another \\
5 & Strong importance of one factor over another \\
7 & Very strong importance of one factor over another \\
9 & Extreme importance of one factor over another \\
$2,4,6,8$ & Intermediate value between two close judgments \\
\hline
\end{tabular}

complex problem into a simple hierarchy. This method is simple, easy, and flexible to apply. The flowchart of the AHP method is shown in Fig. 2. A survey has been conducted for the data collection. The responses have been collected from food processors and researchers working in the food processing supply chain domain. The questionnaire consists of three sections. The first section deals with the general information of the respondents and their respective affiliation backgrounds. Section two is designed to select the most suitable barriers and exploring their significance in the Indian food process industries. Section three helps in finding the priority of concern of the growth barriers chosen in the food processing sectors. The expert has validated the final results.

The steps involved in the AHP application are as follows [29, 38].

a. Select the barriers from the extant literature review. Finalize the barriers by taking the experts' opinions from the researcher, practitioner, and field personnel. The scale used for the pairwise comparison is shown in Table 2.

b. Pairwise comparison of the finalized barriers at farm, distribution, and consumer level by the experts are shown in Tables 3, 4 and 5, respectively. In this research work, ten experts (seven food processors \& three academicians) were contacted for conducting the study. A final decision-making matrix is formulated after taking ten individual responses in matrix form. 
Table 3 Pairwise comparisons of barriers at the farm level

\begin{tabular}{lllllllll}
\hline & FL1 & FL2 & FL3 & FL4 & FL5 & FL6 & FL7 & FL8 \\
\hline FL1 & 1 & 0.25 & 0.33 & 0.25 & 0.20 & 0.33 & 2.00 & 2.00 \\
FL2 & 4.00 & 1 & 0.33 & 1.0 & 1.0 & 0.50 & 3.00 & 3.00 \\
FL3 & 3.00 & 3.00 & 1 & 3.00 & 2.00 & 1.00 & 3.00 & 3.00 \\
FL4 & 4.00 & 1.00 & 0.33 & 1 & 1.00 & 1.00 & 4.00 & 4.00 \\
FL5 & 5.00 & 1.00 & 0.50 & 1.00 & 1 & 3.00 & 4.00 & 3.00 \\
FL6 & 3.00 & 2.00 & 1.00 & 1.00 & 0.33 & 1 & 2.00 & 2.00 \\
FL7 & 0.50 & 0.33 & 0.33 & 0.25 & 0.25 & 0.50 & 1 & 1.00 \\
FL8 & 0.50 & 0.33 & 0.33 & 0.25 & 0.33 & 0.50 & 1.00 & 1 \\
\hline
\end{tabular}

Table 4 Pairwise comparisons of barriers at the distribution level

\begin{tabular}{llllllll}
\hline & DL1 & DL2 & DL3 & DL4 & DL5 & DL6 & DL7 \\
\hline DL1 & 1 & 1.00 & 2.00 & 1.00 & 3.00 & 3.00 & 2.00 \\
DL2 & 1.00 & 1 & 3.00 & 2.00 & 3.00 & 4.00 & 3.00 \\
DL3 & 0.50 & 0.33 & 1 & 0.50 & 3.00 & 3.00 & 2.00 \\
DL4 & 1.00 & 0.50 & 2.00 & 1 & 3.00 & 4.00 & 3.00 \\
DL5 & 0.33 & 0.33 & 0.33 & 0.33 & 1 & 1.00 & 0.50 \\
DL6 & 0.33 & 0.25 & 0.33 & 0.25 & 1.00 & 1 & 0.50 \\
DL7 & 0.50 & 0.33 & 0.50 & 0.33 & 2.00 & 2.00 & 1 \\
\hline
\end{tabular}

Table 5 Pairwise comparisons of barriers at the consumer level

\begin{tabular}{llll}
\hline & CL1 & CL2 & CL3 \\
\hline CL1 & 1 & 0.25 & 1.00 \\
CL2 & 4.00 & 1 & 3.00 \\
CL3 & 1.00 & 0.33 & 1 \\
\hline
\end{tabular}

c. Determine the weights and ranking of all the factors and subfactors. Weights, global ranking, and local ranking of all the factors and subfactors are shown in Table 7.

d. Determination of consistency index (CI) for assessing the consistency in expert judgment by using the relation:

$$
\mathrm{CI}=\frac{\lambda_{\max }-n}{n-1}
$$

where, $\lambda_{\max }$ is the maximum eigenvalue of the matrix, and $n$ is the number of factors/ barriers.

e. Next, find the value of consistency ratio (CR), which is calculated as CI/RI, where $\mathrm{RI}$ is the random consistency index. The above expression calculates the value of 
$\mathrm{CI}$, and the RI value depends upon $n$. RI corresponding to the value of $n$ is shown in Table 6.

f. If the final value of CR is less than 0.1, then results are acceptable means judgments are consistent. If $\mathrm{CR}$ is more than 0.1 , then repeat the procedure. $\mathrm{CR}$ value in the case of farm-level barriers is 0.062. Similarly, the CR value for the distribution and consumer levels was 0.02 and 0.01 , respectively. Hence, our results are acceptable.

\section{Results and discussions}

The novel contribution of this paper is two-prong: first, identification of the barriers, and second, ranking of identified barriers. Eighteen barriers have been identified in the IFPS through extant literature and Delphi analysis. Out of these, eight are at the farm level, seven at the distribution level, and three at the consumer level. The ranking of these barriers is obtained by using the AHP method. The pairwise evaluation matrix for the identified main barriers and the specific factors is constructed to determine their priority or ranking. The final relative weights and ranking of all the factors and subfactors in the IFPS are summarized in Table 7.

Relative weights for all sub-factors have been calculated (see Table 7). Further, for estimating the global weights, each main factor's relative weights are multiplied with its corresponding subfactor weight. For example, for calculating the global weight of subfactor (FL1), factor weight (FL) is multiplied by the corresponding sub factor's relative weight $(0.493 \times 0.056=0.0276)$. Local ranking of subfactors in the particular level (farm, distribution, consumer) based on the relative weights of the subfactors and global ranking has been done based on the sub-factors global weights. The global ranking is the ranking of all the sub-factors based on the global weights. This procedure is already explained in Sect. 4.2 in detail.

Among the main factors, the ranking identified in decreasing order of the relative weights is as follows: farm level (0.493), distribution level (0.311), and consumer level (0.196). This indicates that efforts towards addressing the challenges at the farm level should be the first priority, followed by distribution and consumer levels, respectively. The decreasing order of top five barriers at the farm level factors is rain-dependent farming (FL3 0.239), lack of proper cold storage facilities near the farm (FL5 0.188), lack of proper logistics and handling facilities near the farm (FL4 0.150), unaffordable modernization (FL6 0.141), and conventional methods of farming (FL2 0.131) (refer to Table 7).

Table 6 Random consistency indices (Alonso and Lamata, 2006)

\begin{tabular}{llllllllllll}
\hline $\mathrm{n}$ & 1 & 2 & 3 & 4 & 5 & 6 & 7 & 13 & 14 & 15 & 16 \\
\hline $\mathrm{RI}$ & 0 & 0 & 0.5245 & 0.8815 & 1.1086 & 1.2479 & 1.3417 & 1.5551 & 1.5713 & 1.5838 & 1.5978 \\
\hline
\end{tabular}




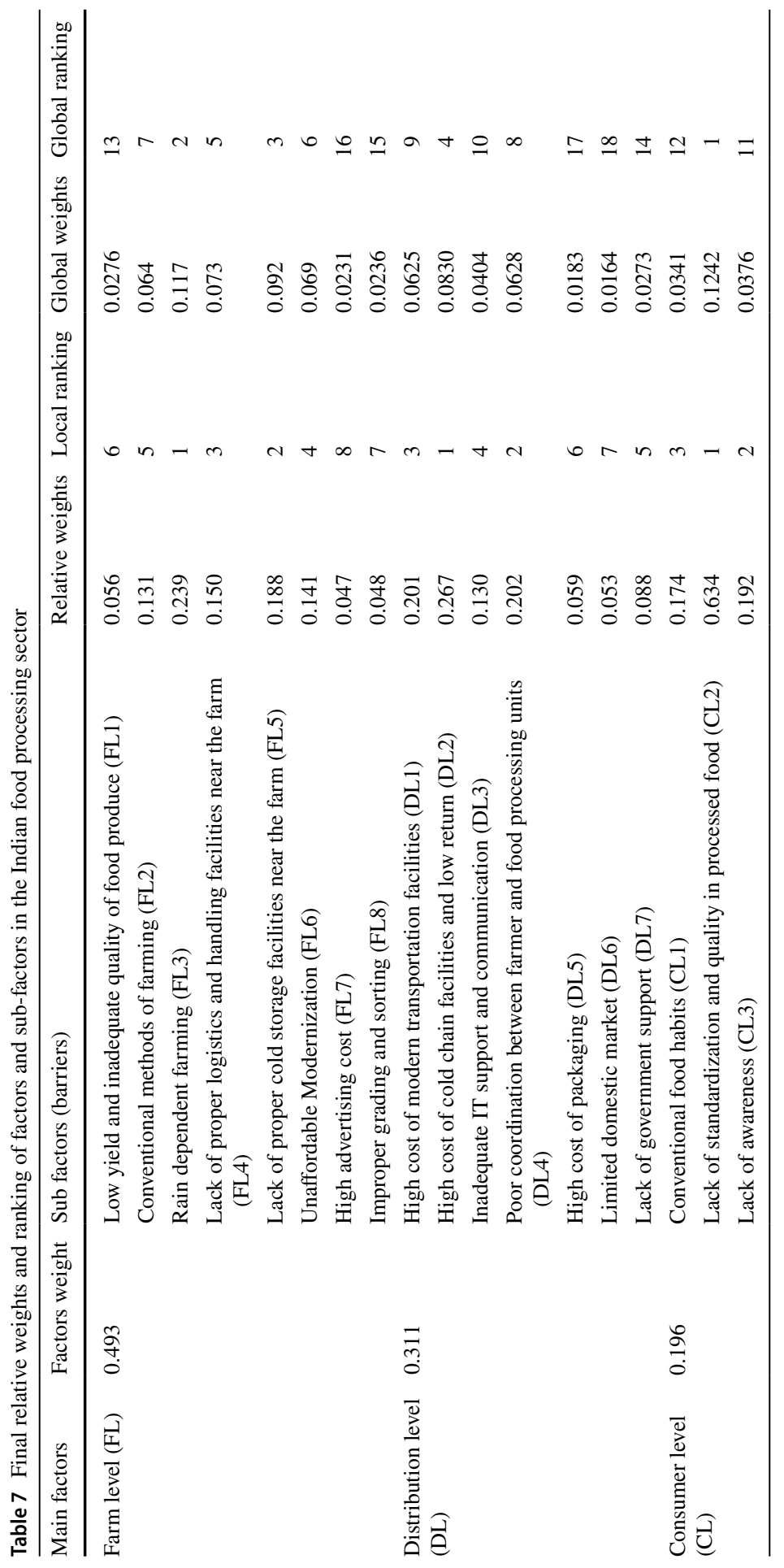


From the above results, it is clear that farm factors are the influential critical factors and need urgent attention from the decision-makers and policymakers to reduce losses at the farm level supply chain. Farm-level is the initial level in the food supply chain. It is also called a post-harvest stage. If the supply chain reduces the losses at this stage, more raw materials would be available to the food process industries. It will further contribute towards increasing the productivity of processing industries. After the farming stage, farm produce goes to the distribution stage. The top five barriers in the decreasing order of the distribution process are high cost of cold chain facilities and low return (DL2 0.267), Poor coordination between farmer and food processing units (DL4 0.202), High cost of modern transportation facilities (DL1 0.201), Inadequate IT support and communication (DL3 0.130), lack of government support (DL7 0.088).

Around $10 \%$ of the perishable items are using cold storage facilities in India at the distribution stage. Cold storage and warehouse facilities are required to reduce wastage and maintain agricultural product quality [1]. Cold storage should be at the accessible route and ensure proper transportation facilities near the cold chain facility. It should also be a nearby processing unit to minimize lead time. Our results suggest that the direct linkage between them is still a major problem. Government and non-government organizations should spread information and help to establish the links between farmers and processing units. Once these links are established, the next step should be to make unorganized farmers join hands through cooperative societies (e.g., Amul) to harness the economies of scale. All players should exchange information for better decision-making [35]. Gardas et al. [18] suggested that if the food processing industries purchase raw material from the farmer directly, it will reduce the intermediaries. This will enhance farmers' income as well as the profitability of the processor. The other two barriers in distribution are the high cost of packaging (DL5) and the limited domestic market (DL6).

The last stage in the IFPS is the consumer level. Ultimately, a food processor earns a profit when the consumer likes it. We find that critical barriers at this stage are lack of standardization and quality in processed food (CL2 0.634), lack of awareness (CL3 0.192), and conventional food habits (CL1 0.174). Traditionally Indian people buy fresh food as compared to packed/processed/preserved food. High processing cost makes processed food unaffordable to low-income people, and sometimes people are not getting value for money because of the poor quality of processed food. However, with the ever-increasing young population in metro cities, the demand for quality processed food is ever-increasing. The results suggest that the critical factor among all three barriers in this stage is the lack of standardization and quality in processed food. Once this is taken care of, the other two barriers will start to weaken down gradually. Hence, the study strongly suggests that food processors should focus their resources in this direction with urgency.

The top five barriers out of eighteen barriers as per global ranking in the Indian food processing sector are as follows (refer to Table 7): Lack of standardization and quality in processed food (CL2), Rain dependent farming (FL3), Lack of proper cold storage facilities near the farm (FL5), High cost of cold chain facilities and low return (DL2), Lack of proper logistics and handling facilities near the farm (FL4). Three barriers out of the top five barriers belong to the farm-level 
factors. These factors are the influential critical factors and need urgent attention from the decision-makers and policymakers to reduce losses at the farm level in the Indian food supply chain. Some other reasons for the slow growth in the IFPS are that most people cannot afford processed food because of the lowincome level, fresh produce preferences compared to packaged food, and most of the people are not yet visiting a supermarket. However, all of these barriers were not investigated together; hence their relative importance was unexplored so far, which is one of the key contributions of this paper.

Among the top ten barriers in the overall global ranking, the contribution of the farm-level barriers, distribution level barriers, and consumer level barriers is $50 \%, 40 \%$, and $10 \%$, respectively. While the contribution of the consumer-level barriers seems the lowest, it is to be noted that one of the factors in the consumer level-Lack of standardization and quality in processed food-is the top-most factor among all eighteen identified factors. Hence, we reiterate that food processors should give quality assurance prime importance. This can be successfully pursued by focusing efforts towards total quality management and lean practices, which produce significant improvements across different sectors [13, 14]. Further, at the farm level, the government should support small farmers. This can be done by providing them subsidies, finance to purchase modern equipment, banking facility, and investments in installing small food processing units at the farm. Awareness about the benefits of the small food processing units of agriculture produces and provides back-end support to farmers should be prioritized in this segment. Recently, Lok Sabha (Parliament of India) passed The Farmers' Produce Trade and Commerce (Promotion and Facilitation) Bill, 2020, and The Farmers' (Empowerment and Protection) Agreement of Price Assurance and Farm Services Bill, 2020 helps the IFPS by providing the direct link to the farmers and industries.

For enhancing food safety systems and standards in the food processing sector, industries should adopt good management practices and good hygienic practices. Also, there is a need to provide the skills and training in food technology on the social front. Land acquisition delays and complex government clearance procedures hamper the growth of the food processing sector. The government should provide single window clearance for the food processing projects and relax non-farming land use permits for the food industry. There is an urgent need to provide cheap credit to the food processing sector to create infrastructure like the cold chain infrastructure, logistics, storage facilities, etc., and constitute the task force to examine the working capital requirements.

The raw material of the food processing sector is seasonal and labor-intensive. There is a need to create a risk fund that mitigates the stress in the food processing sector. The research infrastructure, testing facilities, and traceability systems need to be improved, so that safe food reaches the consumers. The initiative should be taken to boost investment in plant and machinery and promote packaging of the product locally to reduce its overall production cost. There is a need to make a national food processing policy to avoid state and center policies' incompatibility. The urgent need to increase start-ups, testing technologies, and innovation in the Indian food processing sector are also evident for practitioners. 
The Government of India (GoI) has taken many good initiatives for the development of IFPS. The government announced a start-up India scheme to enhance the credit through banks for start-up ventures to develop the food processing sector and job creation. SIDBI (small industries development bank of India) and NABARD (National Bank for Agriculture and Rural Development) provide funds to the agroindustry, food processing sector, and rural development. These banks are also investing in the capital creation, technological innovation, development, and improvement of the product. Through the skill India mission, the government provides required skills and training to the people working in the food processing sector. The food processing sector is one of the vital thrust sectors among the chosen 25 thrust sectors under the Make in India scheme. The Indian government also created an investor portal to attract investment in the food processing sector. GoI established India's regulatory body, food safety, and standards authority of India (FSSAI) in 2008 to take care of the matters associated with food safety and standard practices in India's food sector. The recent farm bill is aimed to help increase trade by removing intermediaries and putting government taxes outside the Agricultural Produce Market Committees (APMC). It is expected to help in promoting interstate and intrastate business and increase the investment in infrastructure development. Our findings reveal that these policies are the need of the day to improve productivity in IFPS and the Indian agriculture sector. Their proper implementation and execution should be taken on priority by policymakers, researchers, and practitioners.

\section{Conclusions and future research directions}

India ranks second in the world in terms of the production of agricultural commodities. Still, India has not utilized its full potential and processes just $2 \%$ of fruits and vegetables globally. A few researchers have attempted to address this underlying problem by identifying the growth barriers of the IFPS; however, their results stand staggered at different levels. This study is a novel and recent attempt to capture the growth barriers to IFPS in an integrated manner by considering all prime factors together-farm level, distribution level, and consumer level. After the extensive literature review and expert opinion using Delphi analysis in the IFPS, a total of eighteen barriers have been found. Out of these, eight are at the farm level, seven at the distribution level, and three at the consumer level. The barriers are then ranked by using AHP. The results indicate that the top barrier at the farm level is rain-dependent farming (FL3 0.239), and the top barrier at the distribution level is the high cost of cold chain facilities and low return (DL2 0.267). The top critical barrier at the consumer level is the lack of standardization and quality in processed food (CL2 0.634) (Table 7). The study suggests that food processors should prioritize their efforts in this direction to make the supply chain more sustainable. The results are relevant for researchers, practitioners, and policymakers. In the Indian context, more investments are needed in the food processing sector to make it globally competitive, and also, there is a significant gap between food production and processing. In the future, other MCDM techniques such as Decision-making trial and evaluation laboratory (DEMATEL), interpretive structural modeling (ISM), structural equation 
modeling (SEM), etc., can also be explored by other researchers. Further, the world is ever-changing, hence after few years, these barriers might evolve with time, and therefore, the avenues of further research in this domain will always exist.

Author contributions All authors contributed to the study conception and design. Material preparation and data collection were performed by GS. Data validation and analysis were performed by GS and Dr. YD. The first draft of the manuscript was written by GS and all authors commented on previous versions of the manuscript. All authors read and approved the final manuscript.

Funding No funding was received to assist with the preparation of this manuscript.

Data availability Data was collected through surveys and expert interviews by the principal author. The data collection for this research is in concordance with disciplinary norms and expectations of the journal.

Code availability Not applicable for this study.

\section{Declarations}

Conflict of interest The authors declare that they have no conflict of interest.

\section{References}

1. Accorsi, R., Gallo, A., Manzini, R.: A climate-driven decision-support model for the distribution of perishable products. J. Clean. Prod. 165, 917-929 (2017)

2. Akkermans, H.A., Bogerd, P., Yücesan, E., Van Wassenhove, L.N.: The impact of ERP on supply chain management: exploratory findings from a European Delphi study. Eur. J. Oper. Res. 146(2), 284-301 (2003)

3. Ali, J.: Productivity and efficiency in Indian meat processing industry: a DEA approach. Ind. J. Agric. Econ. 62(4), 902-2016-66785 (2007)

4. Annual Report I Ministry of Food Processing Industries (2020). https://www.mofpi.nic.in/docum ents/reports/annual-report, accessed on October 13, 2020

5. Bag, S., Anand, N.: Modelling barriers of sustainable supply chain network design using interpretive structural modelling: an insight from food processing sector in India. Int. J. Autom. Logist. 1(3), 234-255 (2015)

6. Babu, D.R., Rao, K.N., Ramesh, E., Sabitha, T.: Awareness on food processing entrepreneurship among engineering faculty. Int. J. Eng. Adv. Technol. (IJEAT) 8958, 1207-1216 (2019)

7. Balaji, M., Arshinder, K.: Modeling the causes of food wastage in Indian perishable food supply chain. Resour. Conserv. Recycl. 114, 153-167 (2016)

8. Chitrakar, B., Zhang, M., Bhandari, B.: Improvement strategies of food supply chain through novel food processing technologies during COVID-19 pandemic. Food Control 125, 108010 (2021)

9. Chengappa, P.G.: Emerging trends in agro-processing in India. Ind. J. Agric. Econ. 59(1), 9022016-68029 (2004)

10. CII-Face Food Processing Report (2019). http://face-cii.in/sites/default/files/food_processing report_2019.pdf, accessed on October 13, 2020

11. Dandage, K., Badia-Melis, R., Ruiz-García, L.: Indian perspective in food traceability: a review. Food Control 71, 217-227 (2017)

12. Das, S., Biswas, B.: Role and prospects of food processing industries in Indian economy - an analysis. In: Pal, M.K. (ed.) Productivity Growth in the Manufacturing Sector, pp. 241-252. Emerald Publishing Limited, Bingley (2021). https://doi.org/10.1108/978-1-80071-094-820211018

13. Daultani, Y., Chaudhuri, A., Kumar, S.: A decade of lean in healthcare: current state and future directions. Glob. Bus. Rev. 16(6), 1082-1099 (2015) 
14. Daultani, Y., Kumar, S., Vaidya, O.S., Tiwari, M.K.: A supply chain network equilibrium model for operational and opportunism risk mitigation. Int. J. Prod. Res. 53(18), 5685-5715 (2015)

15. Dharni, K., Sharma, R.K.: Supply chain management in food processing sector: experience from India. Int. J. Logist. Syst. Manag. 21(1), 115-132 (2015)

16. Dora, M., Kumar, M., Gellynck, X.: Determinants and barriers to lean implementation in food-processing SMEs-a multiple case analysis. Prod. Plan. Control 27(1), 1-23 (2016)

17. Gardas, B.B., Raut, R.D., Narkhede, B.: Modeling causal factors of post-harvesting losses in vegetable and fruit supply chain: an Indian perspective. Renew. Sustain. Energy Rev. 80, 1355-1371 (2017)

18. Gardas, B.B., Raut, R.D., Narkhede, B.: Evaluating critical causal factors for post-harvest losses (PHL) in the fruit and vegetables supply chain in India using the DEMATEL approach. J. Clean. Prod. 199, 47-61 (2018)

19. Gokarn, S., Kuthambalayan, T.S.: Analysis of challenges inhibiting the reduction of waste in food supply chain. J. Clean. Prod. 168, 595-604 (2017)

20. Gupta, K.B.: Consumer behaviour for food products in India. In: 19th Annual World Symposium of the Indian Institute of Management, Bombay, India, pp. 20-21. (2009, June)

21. Joshi, R., Banwet, D.K., Shankar, R.: Indian cold chain: modeling the inhibitors. Br. Food J. 111, 1260-1283 (2009)

22. Kachru, R.P.: Agro-processing industries in India: growth, status and prospects. J. Indones. Agroind. 13(2), 167-181 (2010)

23. Kasso, M., Bekele, A.: Post-harvest loss and quality deterioration of horticultural crops in Dire Dawa Region, Ethiopia. J. Saudi Soc. Agric. Sci. 17(1), 88-96 (2018)

24. Kumar, M., Basu, P.: Perspectives of productivity growth in Indian food industry: a data envelopment analysis. Int. J. Product. Perform. Manag. 57, 503-522 (2008)

25. Kumar, S., Rao, D.U.M., Thombare, P., Kale, P.: Small and marginal farmers of Indian agriculture: prospects and extension strategies. Indian Res. J. Ext. Educ. 20(1), 35-41 (2020)

26. Mahapatra, M.S., Mahanty, B.: India's national food security programme: a strategic insight. Sādhanā 43(12), 194 (2018)

27. Mangla, S.K., Luthra, S., Jakhar, S.K., Tyagi, M., Narkhede, B.E.: Benchmarking the logistics management implementation using Delphi and fuzzy DEMATEL. Benchmark. Int. J. 25(6), 1795-1828 (2018)

28. Mangla, S.K., Sharma, Y.K., Patil, P.P., Yadav, G., Xu, J.: Logistics and distribution challenges to managing operations for corporate sustainability: study on leading Indian diary organizations. J. Clean. Prod. 238, 117620 (2019)

29. Mani, V., Agrawal, R., Sharma, V.: Supplier selection using social sustainability: AHP based approach in India. Int. Strategic Manag. Rev. 2(2), 98-112 (2014)

30. Meena, S.R., Meena, S.D., Pratap, S., Patidar, R., Daultani, Y.: Strategic analysis of the Indian agrifood supply chain. Opsearch 56(3), 965-982 (2019)

31. Parfitt, J., Barthel, M., Macnaughton, S.: Food waste within food supply chains: quantification and potential for change to 2050. Philos. Trans. Royal Soc. B: Biol. Sci. 365(1554), 3065-3081 (2010)

32. Persis, D.J., Venkatesh, V.G., Sreedharan, V.R., Shi, Y., Sankaranarayanan, B.: Modelling and analysing the impact of circular economy; internet of things and ethical business practices in the VUCA world: evidence from the food processing industry. J. Clean. Prod. 301, 126871 (2021)

33. Prajapati, D., Daultani, Y., Cheikhrouhou, N., Pratap, S.: Identification and ranking of key factors impacting efficiency of Indian shipping logistics sector. Opsearch 57, 765-786 (2020)

34. Prajapati, D., Harish, A.R., Daultani, Y., Singh, H., Pratap, S.: A clustering based routing heuristic for last-mile logistics in fresh food E-commerce. Glob. Bus. Rev. (2020). https://doi.org/10.1177/ 0972150919889797

35. Rais, M., Sheoran, A.: Scope of supply chain management in fruits and vegetables in India. J. Food Process. Technol. 6(3), 1 (2015)

36. Rais, M., Acharya, S., Sharma, N.: Food processing industry in India: S\&T capability, skills and employment opportunities. J. Food Process. Technol. 4(9), 1-13 (2013)

37. Rao, C.S., Gopinath, K.A., Prasad, J.V.N.S., Singh, A.K.: Climate resilient villages for sustainable food security in tropical India: concept, process, technologies, institutions, and impacts. Adv. Agronom. 140, 101-214 (2016)

38. Raut, R.D., Gardas, B.B., Kharat, M., Narkhede, B.: Modeling the drivers of post-harvest lossesMCDM approach. Comput. Electron. Agric. 154, 426-433 (2018) 
39. Reddy, A.A., Bantilan, M.C.S.: Competitiveness and technical efficiency: determinants in the groundnut oil sector of India. Food Policy 37(3), 255-263 (2012)

40. Saaty, T.L.: What is the analytic hierarchy process? In: Mitra, G., Greenberg, H.J., Lootsma, F.A., Rijkaert, M.J., Zimmermann, H.J. (eds.) Mathematical Models for Decision Support, pp. 109-121. Springer, Berlin (1988)

41. Sharma, V.K., Chandana, P., Bhardwaj, A.: Critical factors analysis and its ranking for implementation of GSCM in Indian dairy industry. J. Manuf. Technol. Manag. 26(6), 911-922 (2015)

42. Shankar, R., Gupta, R., Pathak, D.K.: Modeling critical success factors of traceability for food logistics system. Transp. Res. Part E: Logist. Transp. Rev. 119, 205-222 (2018)

43. Shelly, M., Kaur, K.: Impacts of food processing industry on economic growth, FDI and exports of India. Pac. Bus. Rev. Int. 7(12), 63-72 (2015)

44. Shukla, M., Jharkharia, S.: Applicability of ARIMA models in wholesale vegetable market: an investigation. Int. J. Inf. Syst. Supply Chain Manag. 6(3), 105-119 (2013)

45. Siddh, M.M., Soni, G., Jain, R.: Perishable food supply chain quality (PFSCQ): A structured review and implications for future research. J. Adv. Manag. Res. 12(3), 292-313 (2015)

46. Simms, C., Trott, P., van den Hende, E., Hultink, E.J.: Barriers to the adoption of waste-reducing eco-innovations in the packaged food sector: a study in the UK and the Netherlands. J. Clean. Prod. 244, 118792 (2020)

47. Singh, G., Sahu, R.: A bibliometric analysis on agriculture 4.0. NOLEGEIN-J. Oper. Res. Manag. 2(2), 6-13 (2019)

48. Singh, G., Tyagi, V.V., Singh, P.J., Pandey, A.K.: Estimation of thermodynamic characteristics for comprehensive dairy food processing plant: an energetic and exergetic approach. Energy 194, $116799(2020)$

49. Singh, S.P., Tegegne, F., Ekanem, E.P.: The food processing industry in India: challenges and opportunities. J. Food Distrib. Res. 43(856-2016-58050), 81-89 (2012)

50. Thulasiraman, V., Nandagopal, M.S.G., Kothakota, A.: Need for a balance between short food supply chains and integrated food processing sectors: COVID-19 takeaways from India. J. Food Sci. Technol. (2021). https://doi.org/10.1007/s13197-020-04942-0

51. Viswanadham, N.: Can India be the food basket for the world. Achiev. Rural Glob. Supply Chain Excell. 1, 1-16 (2006)

52. Vrat, P., Gupta, R., Bhatnagar, A., Pathak, D.K., Fulzele, V.: Literature review analytics (LRA) on sustainable cold-chain for perishable food products: research trends and future directions. Opsearch 55(3-4), 601-627 (2018)

Publisher's Note Springer Nature remains neutral with regard to jurisdictional claims in published maps and institutional affiliations. 